\title{
Induction-, test-, and comparison-figure interactions under illusion and figural aftereffect conditions*
}

\author{
ROGER B. HOWARD, GARY W. EVANS $\dagger$, and JOHN K. McDONALD \\ Colgate University, Hamilton, New York 13346
}

\begin{abstract}
Ganz $(1966 \mathrm{a}, \mathrm{b})$ has argued that an induction figure will displace a test figure placed near it under both illusion and figural aftereffect conditions. The data from Experiments I and II show that most of the illusion produced by the figures studied by Ganz results from an interaction between the comparison and induction figures. The data from Experiment III suggest that both the test and comparison figures interact with the induction figure under figural aftereffect conditions. Although the induction-test figure interactions do not contradict Ganz's model, the induction-comparison figure interactions cannot be explained by it. The data also suggest that researchers should be extremely cautious in drawing conclusions about the processes underlying illusions and figural aftereffects unless they are confident that there is no interaction between the induction and comparison figures.
\end{abstract}

Ganz's (1966a, b) model of illusions and figural aftereffects (FAEs) has been extensively criticized for its failure to explain many phenomena. According to the model, FAEs are simultaneous illusions in which the trace of the test $(T)$ figure is displaced away from the afterimage of the induction (I) figure. ${ }^{1}$ Thus, illusions and FAEs should be comparable functions of most independent variables. Several authors (e.g., Pollack, 1967; Over, 1968; Wagner, 1968; Howard, 1971) have pointed out that this prediction is incorrect for the Mueller-Lyer, concentric circles, and related configurations which appear to produce displacement of the $\mathrm{T}$ figure toward the I figure over a wide range of illusion conditions and displacement away under comparable FAE conditions.

There are a few stimulus configurations, however, for which the model apparently predicts similar illusion and FAE functions correctly. If the $I$ and $T$ figures shown in Fig. 1a are presented simultaneously, the $T$ figure will appear displaced to the right relative to the comparison (C) figure. Ganz (1966b) has shown that this illusion is an inverted-U function of the interfigural distance (IFD), and is virtually identical to the FAE function produced by presenting the I before the T figure (Pollack, 1958).

Since this configuration is one of the few still explainable by Ganz's model, it is crucial to note an apparent discrepancy between the model's predictions and the illusion. According to the model, the $T$ figure is displaced away from the area previously stimulated by the I figure and hence the $\mathrm{T}$ and $\mathrm{C}$ figures are not aligned. If the $\mathrm{T}$ figure is now moved so that it touches the I figure as in Fig. $1 \mathrm{~b}$, the model predicts that the $T$ figure should not be displaced and no illusion should occur. The first prediction is confirmed by the obvious fact that no gap appears between the I and $T$ figures. Yet

*This research was supported in part by grants to the first author from the Colgate Research Council and from the Sloan Foundation.

Now in the Department of Psychology, University of Massachusetts. Amherst. Massachusetts 01002. many Os report that the left edge of the $C$ figure appears to the left and below the right edge of the I figure. If this observation is correct, then the illusion measured by the relative locations of the $\mathrm{T}$ and $\mathrm{C}$ figures may reflect interactions between the $\mathrm{I}$ and $\mathrm{C}$ rather than between the $I$ and $T$ figures. Experiment $I$ was designed to quantify this observation.

\section{EXPERIMENT I}

\section{Method}

\section{Subjects}

The 12 Ss were 5 naive male and 5 naive female volunteers and 2 of the authors (R.B.H. and J.K.M.).

\section{Procedure}

The stimuli were drawn on a single $15.2 \times 22.8 \mathrm{~cm}$ white card. The configuration is shown in Fig. $1 \mathrm{~b}$, and its dimensions were approximately twice those shown in the figure.

Each $S$ was asked to judge the relative locations of the I and $T, I$ and $C$, and $T$ and $C$ figures by indicating whether the inside contours of each pair of figures were aligned or misaligned and then by drawing a horizontal line that had a length equal to the misalignment. All judgments were made while the $S$ held the card and fixated on the lower right-hand corner of the square. $A$ randomized Latin square was used to counterbalance the order of the three pairwise comparisons. All viewing was binocular.

\section{Results}

Eleven of the 12 Ss reported that the $\mathrm{C}$ and I figures overlapped in the horizontal dimension an average of $1.1 \mathrm{~mm}$ (about $6 \mathrm{~min}$ of visual arc). The other $\mathrm{S}$ saw no illusion. Nine Ss saw the left edge of the $C$ figure to the left and the left edge of the $T$ figure to the right of alignment, 2 saw the reverse misalignment, and 1 saw the $\mathrm{T}$ and $\mathrm{C}$ figures aligned. The mean misalignment was $0.97 \mathrm{~mm}$. Both differences are significant at the .05 level, as indicated by $t$ tests. Only 2 Ss reported any $T$ and I figure misalignment, and they reported that the 
a<smiles></smiles>

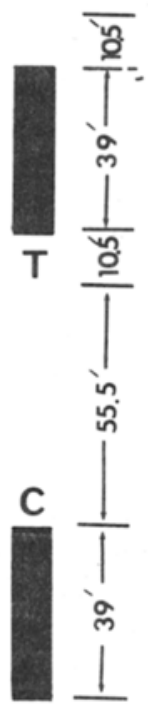

b

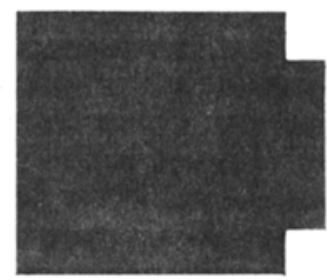

Fig. 1. Two stimulus configurations used in the experiments and their dimensions for Experiments II and III. two figures overlapped rather than separated. The average misalignment was $-0.19 \mathrm{~mm}$. Thus, the illusion with $0 \mathrm{~min}$ IFD is not produced by a simple interaction between the I and T figures. Since Ganz's model predicts no illusion under these conditions, it seems reasonable to conclude that it cannot explain this effect.

\section{EXPERIMENT II}

It is possible that Ganz's model may correctly describe one component of the illusion. Although it cannot explain the misalignment of the I and $\mathrm{C}$ figures, it correctly predicts that there should be no illusion between the $I$ and $T$ figures at $0 \mathrm{~min}$ IFD. If the illusion contains two components, an I-T and an I-C interaction that combine to produce the total misalignment between the $\mathrm{T}$ and $\mathrm{C}$ figures, then Ganz's model may provide an adequate description of the I-T interaction. We tested this hypothesis in Experiment II by having each $\mathrm{S}$ make judgments of the linear separation between each pair of the three figures at different IFDs.

\section{Method}

\section{Subjects}

The Ss were 45 male students from an introductory psychology course at Colgate University. They received course credit for their participation.

\section{Moterials}

The stimuli were drawn in black ink on $15.2 \times 22.8 \mathrm{~cm}$ white cards and were presented in the second field of an Iconix three-field tachistoscope. The dimensions of the configuration are shown in Fig. 1a. Each $S$ estimated the distance between each pair of figures by the method of recognition in which he selects a pair of parallel lines from a wall chart which have the same relative separation as the figures being judged (Fehrer \& Ganchrow, 1963). The chart was made of heavy white posterboard. The lines on the chart were drawn in ink, were $2 \mathrm{~cm}$ long, and subtended $60 \mathrm{~min}$ of arc. They were arranged in two columns, with the separation between the lines increasing from 0 to $120 \mathrm{~min}$ in 3-min steps.

Design

The independent variables were the IFD $(0,3,9,15,30$, and $60 \mathrm{~min}$ of $\mathrm{arc}$ ) and the S's task (three experimental tasks and one control task). The experimental tasks were to judge the distance between the $I$ and $T$, the $I$ and $C$, and the $T$ and $C$ figures. These will be referred to as the IT, IC, and TC tasks, respectively. Although the $S$ performed only one task on each trial, all three stimuli were presented. The TC control task was to judge the separation between pairs of $T$ and $C$ figures presented without the I figure.

Each $S$ was presented with eight lists of trials. There were two lists for each task, and each list contained one trial at each of the six IFDs. The experimental session was divided into two halves by a $2-\mathrm{min}$ rest period. One list of items for each task was presented in a random order in the first half. The remaining four lists were presented in the second half in the reverse order so that serial order effects were counterbalanced across the session. The trials within each list were randomized. The first list was preceded by five practice trials. Each subsequent list was preceded by two practice trials. The figures were always presented for $10 \mathrm{sec}$ with a luminance of $21 \mathrm{~mL}$. All viewing was monocular with the dominant eye.

The $S$ was instructed to fixate on the lower right corner of the I figure during the $10-\mathrm{sec}$ induction period, and then to select the pair of lines from the wall chart which had the same relative separation as the figures he was judging. When he was judging the IC or TC separation. the $S$ was asked to imagine that the $C$ figure was raised up until it was parallel with the $I$ and $T$ figures. and then to judge the resulting separation. No $S$ reported difficulty with this task. 
Fig. 2. Mean displacements of figures in Experiment II as functions of the interfigural distances (IFDs), both in minutes of visual arc. A " 5 " or " 1 " beside a point indicates that the transformed scores $\left[X^{\prime}=\log _{10}(X+5)\right]$ are significantly different from zero displacement, with $\alpha=$ 0.05 or 0.01 , respectively.

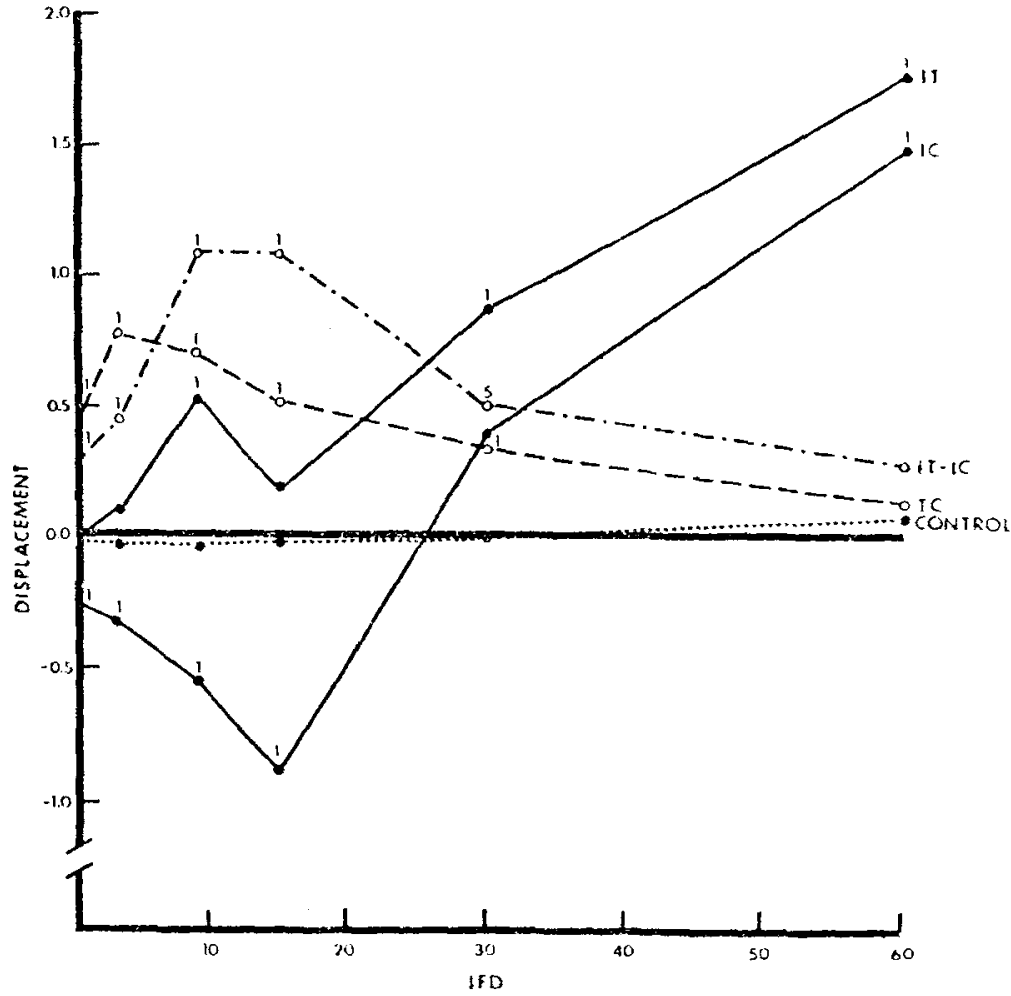

\section{Results}

Figure 2 shows the mean displacements of the figures as functions of the IFD. In the IT and IC conditions, a positive score indicates that the distance between the figures was overestimated. In the TC conditions, a positive score means that the $\mathrm{C}$ figure appeared to the left and the $\mathrm{T}$ figure to the right of alignment.

The formal statistics reported below are $t$ tests between the mean displacement at a single data point and a base level of zero displacement. To compute t, we must assume or demonstrate that the mean and variance of the sample are independent. Since t tests are computed separately for each data point, we might assume that the mean and variance for any point are independent without considering the data at other points. Nevertheless, a high correlation between the means and variances across data points within a condition would suggest that this assumption is unwarranted and that the data should be transformed before computing $t$.
Table 1 shows the ranges of variances and their correlations with the mean displacements from each condition. The correlations are quite large, with the exception of the IT-IC difference function. $F_{\max }$ tests (Winer, 1962) showed that the other four variance ranges were significant $(p<.05)$. The data were then transformed according to the formula $\mathrm{X}^{\prime}=\log _{1_{0}}(\mathrm{X}+5)$. where $X$ is the original displacement score, $X^{\prime}$ is the transformed score, and 5 is added to $X$ to avoid negative and zero numbers. $F_{\max }$ tests of the transformed scores showed that the ranges of variances within each condition were not significant. The $t$ tests were therefore computed using the transformed scores and a null value of $\log _{10}(0+5)=0.699$. A " 5 " or a " 1 " at a point in Fig. 1 indicates that the $t$ test was significant, with $\alpha=$ 0.05 or 0.01 , respectively. No number indicates that the $t$ test was not significant.

The TC function is very similar to the one described by Ganz (1966b). Its maximum value is at an IFD of $3 \mathrm{~min}$. There is a significant amount of illusion at 0 min IFD which supports the results of Experiment I. The

Table 1

The Ranges of Variances and the Correlations Between Variances and Means for the Five Conditions of Experiments Il and III

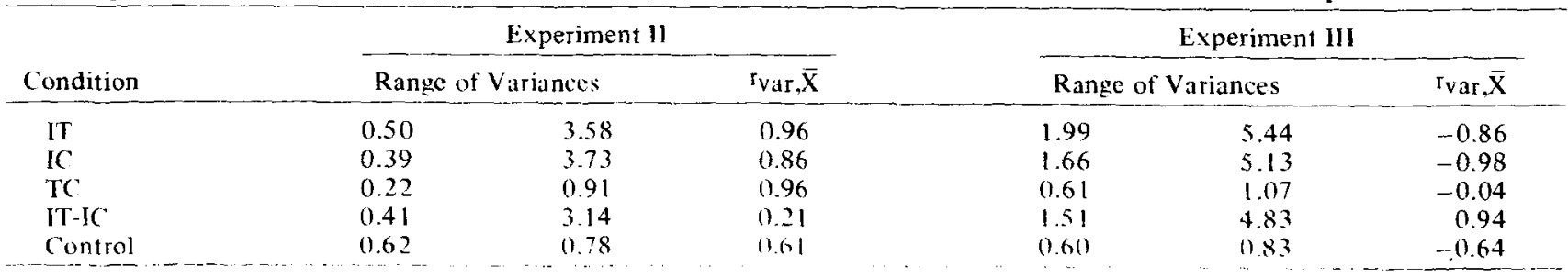




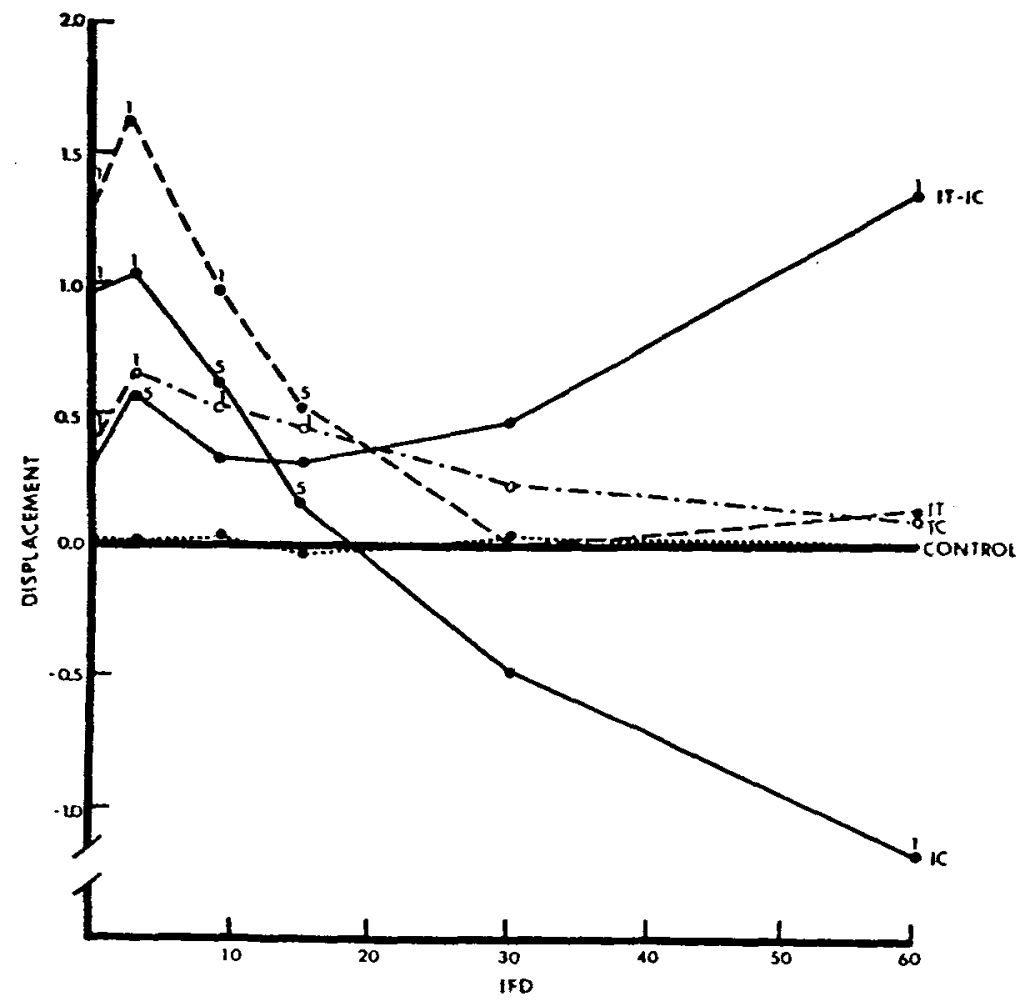

Fig. 3. Mean displacements of figure in Experiment III as functions of the interfigural distances (IFDs), both in minutes of visual arc. $A$ " 5 " or " 1 " beside a point indicates that the transformed scores $\left[X^{\prime}=\log _{10}(X+10)\right]$ are significantly different from zero displacement, with $\alpha=$ 0.05 or 0.01 , respectively.

control function shows little perceptual or response bias either to the left or right.

There appear to be at least two factors that determine the shape of the TC function and a third that is unique to the IC and IT functions. First, the I and $\mathrm{C}$ figures appear closer together than they actually are. The function relating IC displacement to IFD decreases sharply to $15 \mathrm{~min}$ IFD, then rises rapidly to become positive at $30 \mathrm{~min}$. Since a negative value indicates reduced separation of the $I$ and $C$ figures and since this would increase the overall illusion, it seems likely that relative displacement of the $I$ and $C$ figures is an important component of the overall illusion measured by TC displacement.

Second, there is a weak, but significant, increase in the apparent separation of the $I$ and $T$ figures. The IT function is zero at $0 \mathrm{~min}$ IFD. It reaches a maximum at an IFD of $9 \mathrm{~min}$, decreases, then increases sharply. Thus, the displacement of the $T$ figure predicted by Ganz may be present, but it is overshadowed by the interaction between the $I$ and $C$ figures.

The third component appears to cause an overestimation of large IFDs. As the IFD increases beyond $15 \mathrm{~min}$, the IT curve suddenly reverses and both IT and IC functions have large positive values. This effect is sometimes found in psychophysical studies of magnitude under similar conditions (e.g., Tresselt \& Mayzner, 1967; Helson, 1964).

When the three effects are combined by subtracting the IC function from the IT function, we obtain a crude approximation to the TC function. It would appear, therefore, that interactions between both the IT and IC configurations contribute to the illusion, but that the IC interaction is the stronger of the two.

\section{EXPERIMENT III}

The results from Experiment II indicate that there are at least two components of the illusion measured by TC displacement. It would seem reasonable to suppose that there might also be two components of the FAE as well. Experiment III was designed to explore this hypothesis.

\section{Method}

The Ss were 40 male students from an introductory psychology course at Colgate University. They received course credit for their participation.

The I figure was drawn as described above and shown in the second field of the tachistoscope. Each pair of $T$ and $C$ figures was drawn on a separate white card and shown in the third field. The duration was $10 \mathrm{sec}$ for the I figure and $100 \mathrm{msec}$ for the $T$ and $C$ figures. The design and procedure for Experiments II and III were identical in all other respects.

\section{Results}

Figure 3 shows the mean displacement of the figures, plotted in the same manner as the data from Experiment II shown in Fig. 2. Table 1 shows that the variances and the means within a condition are correlated with each other. $\mathrm{F}_{\max }$ tests indicated that the ranges of variances in the IT, IC, and IT-IC conditions 
were significant $(p<.05)$. The data were therefore transformed according to the equation $X^{\prime}=$ $\log _{10}(X+10)$. $F_{\max }$ tests on the transformed scores showed that the ranges of variances were not significant. The $t$ tests were based on these transformed scores and a null value of $\log _{10}(0+10)=1.00$.

As in Experiment II, the TC function has its peak at $3 \mathrm{~min}$ of arc and then declines. This confirms the similarity between the illusion and FAE TC functions reported by Ganz (1966b) and Pollack (1958), respectively, although our functions do not decline as rapidly as theirs. The control TC function shows no systematic or significant deviation from zero.

The IT functions from the FAE and illusion experiments are similar but not identical. The peak of the FAE function occurs at $3 \mathrm{~min}$ of visual arc rather than $9 \mathrm{~min}$, and thus is a better approximation to the $\mathrm{TC}$ function. Further, the maximum is nearly three times higher than the illusion function. Finally, although the FAE function tends to increase once again at large separations, it is not as strong as the increase in the illusion function.

Perhaps the greatest differences between Experiments II and III are in the IC conditions. In Experiment II, the $I$ and $C$ figures appeared closer together than they actually were at small IFDs and further away at larger IFDs. The effect in Experiment III is exactly the opposite. In addition, the peak of the FAE function is at $15 \mathrm{~min}$ in Experiment II but has shifted to $3 \mathrm{~min}$ in Experiment III. Thus, the processes affecting the $\mathrm{I}$ and $\mathrm{C}$ figure judgments under FAE and illusion conditions act in opposite directions.

The tendency to overestimate the separation at larger IFDs seems either to have been neutralized or reversed. The Ss underestimated the IC separation substantially at both 30- and 60 -min IFDs. Although the IT function does not become negative, it is nevertheless considerably lower than in Experiment II. As a resuit, the IT-IC function has less deviation from the TC function at small IFDs than the corresponding :illusion function and greater deviation at large IFDs.

\section{DISCUSSION}

In general, the data may be interpreted to support Ganz's prediction that there is an interaction between the $I$ and $T$ figures under both FAE and illusion conditions. There are certainly differences in the two functions, but the significance of this finding is obscure because the illusion and FAE conditions are inevitably different. By definition, the $I$ and $T$ figures are presented simultaneously in illusion and successively in FAE conditions. It is unrealistic to suppose that even equivalent processes would produce exactly the same functions when the trace of the I tigure begins decaying atier the removal of the I figure in the FAE conditions (lkeda \& Obonai. 105.3), but remans supported by the sensory input in the illusion conditions. Furthes. successive presentation of adjacent figures produces apparent motion (Graham, 1966; Howard, 1972a). which presumably is not present in illusions. Illusions and FAEs wou'd also be accompanied by different patterns of eye movements (e.g., Ganz, 1966b). Finally. the tendency to overestimate large IFDs was different in FAE and illusion conditions. Thus, the similarities between the functions are adequate, considering the many ways they could have been distorted, and they cannot be considered as infirming Ganz's model.

It is also possible for Ganz's model to explain the FAE between the $I$ and $C$ figures, although the argument is not convincing. In the model, FAEs result from interactions between neurons that respond to parallel lines. Although the $\mathrm{I}$ and $\mathrm{C}$ lines do not overlap in this experiment, they might excite the upper and lower portions of the receptor fields of the same neurons. Hubel and Wiesel (1963) have found receptor fields with excitatory portions as long as $2.4 \mathrm{deg}$ in the cat. This is more than enough to span the $2 \mathrm{deg}$ of vertical distance covered by the I and $C$ figures. Since part of each line would frequently fall beyond the receptor field, the neurons would respond less vigorously to the $I$ and $C$ figures than to the I and $\mathrm{T}$ figures that would fit within the receptor field. This might explain the weaker FAE between the former two figures. Nevertheless, Hubel and Wiesel (1968) found that simple and complex cells in the macaque and spider monkey have receptor fields with linear dimensions no greater than $3 / 4 \mathrm{deg}$ and $2 \mathrm{deg}$, respectively. Although man is not directly related to either cat or monkey, direct cortical stimulation suggests that neurons in his visual cortex are more similar to the monkey (cf. Brindley \& Lewin, 1968). Thus, it is questionable whether the IC interaction can be handled by the neural structures postulated by Ganz.

In any event, it is clear that Ganz's model cannot explain the new illusion between the $I$ and $C$ figures. The model is designed to explain repulsion between contours and thus cannot explain a decrease in their separation under any conditions (cf. Howard, 1971). It is interesting to note that the concentric circles and Mueller-Lyer configurations also produce FAEs and illusions with opposite signs. It seems likely that the same processes are operating on all three configurations despite their structural dissimilarities. 2

Finally, we would like to point out the potentially damaging results of assuming that $C$ figures do not enter into illusions and FAEs. We have shown that there is an interaction between the $I$ and $C$ figures in one configuration. Howard (1972b) has pointed out the serious interactions in the data collected with parallel lines used at $I, T$, and $C$ figures. If other data also contain similar interactions which distort the magnitudes and shapes of our functions. then precise mathematical models of the underlying processes such as that proposed by Ganz (1966b) are founded on very shaky data indeed. The analysis of ic interations seens in as to be one of the most persing needs in the study of misperceptions. 


\section{REFERENCES}

Brindley, G., \& Lewin, R. Sensations produced by electrical stimulation of the visual cortex. Journal of Physiology, 1968, 196, 479-493.

Fehrer, E., \& Ganchrow, D. Effects of exposure variables on figural aftereffects under tachistoscopic presentation. Journal of Experimental Psychology, 1963, 66, 506-513.

Ganz, L. Is the figural aftereffect an aftereffect? A review of its intensity, onset, decay, and transfer characteristics. Psychological Bulletin, 1966a, 66, 151-165.

Ganz, L. The mechanism of the figural aftereffect. Psychological Review, 1966b, 73, 128-150.

Graham, C. H. Perception of movement. In C. H. Graham (Ed.), Visual perception. New York: Wiley, 1966. Chap. 20, pp. 575-588.

Helson, H. Adaptation-level theory. New York: Harper, 1964.

Howard, R. B. Neurophysiological models of figural aftereffects and visual illusions. Psychonomic Monograph Supplements, $1971,51,57-72$.

Howard, R. B. Some differences among figural aftereffects, apparent motion, and paracontrast. Perception \& Psychophysics, 1972a, 12, 327-332.

Howard, R. B. Complete assimilation of briefly presented lines. Canadian Journal of Psychology, 1972b, 26, 259-267.

Hubel, D. H., \& Wiesel, T. N. Shape and arrangement of columns in cat's striate cortex. Journal of Physiology, 1963, 165, 559-568.

Hubel, D. H., \& Wiesel, T. N. Receptive fields and functional architecture of monkey striate cortex. Journal of Physiology, $1968,195,215-243$.

Ikeda, H., \& Obonai, T. The quantitative analysis of figural after-effect: 1 . The process of growth and decay of figural after-effect. Japanese Journal of Psychology, 1953, 24, 59-68.

Over, R. Explanations of geometric illusions. Psychological Bulletin, 1968, 70, 545-563.

Pollack, R. H. Comment on "Is the figural aftereffect an aftereffect?" Psychological Bulletin, 1967, 68, 359-361.

Pollack, R. H. Figural aftereffects: Quantitative studies of displacement. Australian Journal of Psychology, 1958, 10, 269-277.

Tresselt, M. E., \& Mayzner, M. S. Anchoring and time-error. Psychonomic Monograph Supplement, 1967, 2, 39-43.
Wagner, H. L. The illusions and Ganz's theory of contour displacements. British Journal of Psychology, 1968, 59, 361-367.

Winer, B. J. Statistical principles in experimental design. New York: McGraw-Hill, 1962.

\section{NOTES}

1. The term illusion refers to a distortion in one visual figure resulting from the simultaneous presentation of another figure. A figural aftereffect (FAE) is a distortion in the second of two successively presented visual figures. Traditionally, the figure which presumably causes the distortion is called the inducing (I) figure and the figure which is presumably distorted is called the test (T) figure. In order to estimate the magnitude of the distortion, a comparison (C) figure is presented simultaneously with the $T$ figure in such a way that it is presumably unaffected by the I figure. Obviously, all three figures interact in the experiments reported here, and so it is important to keep the "presumablys" in the above definitions in mind when applying them to the stimulus configuration. The interfigural distance (IFD) refers to the spatial separation of the I from the $T$ contour.

2. Howard (1971) has presented a model of illusions and FAEs which argues that there are at least two different processes involved in the two phenomena. One process produces size or extent distortions and dominates under illusion conditions. The other is very similar to Ganz's contour-interaction process which dominates under FAE conditions. Thus, there is a striking resemblance between the two processes found here and those predicted by Howard's model. Unfortunately, the uncertainty in the data because of the $S s^{\prime}$ tendencies to misjudge large extents is such that it seems premature to expand the model to handle these data. We are now attempting to devise methods for obtaining pure and independent measurements of the displacements of $I, T$, and $C$ figures. We will consider the theoretical implications of the two phenomena when we have a better grasp of the true functions and the nature of the attribute being distorted.

(Received for publication November 3, 1972; revision received A pril 10, 1973.) 